\title{
Aerobic treatment of selective serotonin reuptake inhibitors in landfill leachate
}

\author{
Ove Bergersen ${ }^{1 *}$, Kine Østnes Hanssen ${ }^{2}$ and Terje Vasskog ${ }^{2,3}$
}

\begin{abstract}
Background: Pharmaceuticals used in human medical care are not completely eliminated in the human body and can enter the municipal sewage sludge system and leachate water from landfill both as the parent compound and as their biologically active metabolites. The selective serotonin reuptake inhibitors (SSRIs) have a large potential for unwanted effects on nontarget organisms in the environment. Leachates from active or old closed landfills are often treated with continuous stirring and simple aeration in a pond/lagoon before infiltration into the environment. The aim of this work was to simulate the reduction of five SSRIs (citalopram, fluoxetine, paroxetine, sertraline and fluvoxamine) and three of their metabolites (desmethylcitalopram, didesmethylcitalopram and norfluoxetine) during aerobic treatment of leachate from landfills. This landfill leachate-simulation experiment was performed to see what happens with the pharmaceuticals during aerated treatment and continuous stirring of landfill leachate for $120 \mathrm{~h}$. It is important to establish whether different pollutants such as pharmaceuticals can be removed (oxidized or otherwise degraded) or not before infiltration into the environment.
\end{abstract}

Results: All the SSRIs had a significant concentration reduction during the aeration treatment process. Total SSRI concentrations were reduced significantly during aerobic treatment, and the individual SSRIs were reduced by $89 \%$ to $100 \%$ after $120 \mathrm{~h}$. Among the high-concentration samples, fluoxetine $\left(10 \mathrm{mg} \mathrm{L}^{-1}\right)$ was the least degraded with 93\% concentration reduction. Among the low-concentration samples, paroxetine was the least degraded with 89\% concentration reduction. Fluvoxamine and citalopram were most effectively eliminated and were completely removed from both the high- and low-concentration samples. The samples were also investigated for the metabolites desmethylcitalopram, didesmethylcitalopram and norfluoxetine but only norfluoxetine in the high-concentration fluoxetine sample was detected.

Conclusions: Our results suggest that aeration is an effective method for eliminating pharmaceuticals such as SSRIs from landfill leachate water. Comparing the results of all SSRIs with different treatment methods, paroxetine and fluvoxamine seem to be the easiest compounds to eliminate independent of method, while fluoxetine and sertraline seem to be the most stable.

Keywords: Aeration; Biological treatment; Environment; Landfill leachate; Pharmaceuticals; SSRI

\section{Background}

For several years, the occurrence of pharmaceuticals and personal care products (PPCPs) in the aquatic environment has been recognized as one of the emerging issues in environmental risk assessment [1-4]. Pharmaceuticals used in human medical care are not completely eliminated in the human body and can enter the municipal sewage sludge system both as the parent compound and

\footnotetext{
* Correspondence: ove.bergersen@bioforsk.no

${ }^{1}$ Norwegian Institute for Agricultural and Environmental Research (Bioforsk), Soil and Environment Division, Fredrik A Dahls vei 20, N-1432 Ås, Norway Full list of author information is available at the end of the article
}

as their biologically active metabolites. These compounds have a large potential for unwanted effects on nontarget organisms in the environment. Several investigators have examined the removal of pharmaceutical compounds during the passage through municipal sewage treatment systems [5-8]. Effluent concentrations and elimination rates for different compounds vary significantly. Various pharmaceutical compounds have been detected in concentrations up to $\mu \mathrm{g} \mathrm{L}^{-1}$ in sewage effluents, downstream of sewage treatment plants and in surface and groundwater $[2,9,10]$. In addition to sewage treatment plants, landfill sites where unused drugs and different

\section{Springer}


personal care products have been disposed may release these compounds into the environment. There are several old landfill sites that were established when the disposal of such compounds through garbage was tolerated, and drugs have been detected in leachates from such municipal landfills [11]. Leachates from landfill sites are also known to penetrate down to the groundwater causing pollution [12].

Six selective serotonin reuptake inhibitors (SSRIs) are on the Norwegian market today, fluoxetine, fluvoxamine, paroxetine, sertraline, citalopram and escitalopram (the pure S-enantiomer of citalopram). SSRIs are typically used as antidepressants and are used to treat conditions such as depression, anxiety disorders and some personality disorders. The total consumption of SSRIs has slowly increased in Norway the last years, although when adjusted to population growth, the number of SSRI users has been relatively stable at just below $4 \%$ of the population. Citalopram/escitalopram is most widely distributed and constitutes approximately $591 \mathrm{~kg}$ of the total amount, while sertraline with its higher defined daily dosage is sold in the largest amounts contributing with approximately $621 \mathrm{~kg}$ [13]. SSRIs have been found in wastewater in Norway $[8,14]$, and it is reasonable to believe that not all pharmaceuticals are used or delivered back to the pharmacies but might end up on landfill sites through private garbage disposal. Contaminants from landfill sites might reach the environment through leachate water run-off, and water soluble chemicals can reach the aquatic ecosystems or the groundwater. SSRIs have been shown to have a number of unwanted effects on aquatic organisms, such as the behavioural effect fluoxetine has on fish [15] and the induction of spawning and parturition in bivalves $[16,17]$. Fluoxetine is probably the most studied SSRI when it comes to effects on nontarget organisms, but effects from the other SSRIs have been found as well.

Depletion of SSRIs in sewage sludge has previously been found during an aerobic composting process [18]. Vasskog [18] showed that the depletion rate was highest for fluoxetine $\left(1.23 \mathrm{mg}(\mathrm{kg} \mathrm{ash} / \text { day })^{-1}\right)$ and paroxetine $(1.31 \mathrm{mg}$ $\left.(\mathrm{kg} \mathrm{ash} / \text { day })^{-1}\right)$ and lowest for citalopram $(0.88 \mathrm{mg}(\mathrm{kg}$ $\mathrm{ash} /$ day $)^{-1}$ ). In addition, three out of four known SSRI metabolites were detected in all compost samples, and two of them showed a significant increase in concentrations during the composting period.

PPCPs have also been investigated under anaerobic digestion of sewage sludge [19-22], but SSRIs were not part of these investigations. Carballa et al. [19] observed high removal efficiencies for antibiotics, natural estrogens, musk and naproxen, while for example carbamazepine showed no elimination under anaerobic treatment of sewage sludge. Vieno et al. [20] also observed no elimination of carbamazepine in their anaerobic treatment of raw sewage, while fluoroquinolones were eliminated by $>80 \%$.
Beta-blockers were found to be eliminated less than $65 \%$. Degradation was found for acetylsalicylic acid, while a mixture of degradation and abiotic removal mechanisms on other pharmaceuticals was observed during an anaerobic degradability study by Musson et al. [21]. The fate of hormones and pharmaceuticals during combined anaerobic treatment and nitrogen removal in black water has been investigated by de Graaff et al. [23]. They found that only a few compounds were partly removed, and anaerobic treatment was effective only to remove the majority of paracetamol. Falås et al. [24] have demonstrated that there are large variations in removal of different pharmaceuticals within the same pharmaceutical class as well in activated sludge. In this experiment, the nonsteroidal antiinflammatory drugs (NSAIDs) ibuprofen and naproxen showed the highest removal rates, while diclofenac, mefenamic acid and clofibric acid showed little or no removal. Bergersen et al. [25] have shown that anaerobic treatment of sewage sludge gives a reduction in SSRI concentrations from $32 \%$ (fluoxetine) to $98 \%$ (citalopram) in a 24-day experiment, again demonstrating large variations within the same pharmaceutical class.

Eggen et al. [26] have described that PPCPs from old landfill leachate with treatment based on aeration and sedimentation may represent a significant source of concern for new and emerging pollutants in groundwater.

To our best knowledge, no studies have been conducted on SSRIs in treatment of aerated landfill leachate. When pharmaceuticals enter the environment through landfill leachate systems, they may either be found in the water phase or bound to particles. Landfill leachate aeration ponds could treat the water via aeration and particulate matter sedimentation.

Based on earlier results showing that the removal of SSRIs from sewage sludge is different during aerobic and anaerobic treatment, it was interesting to compare this with what would happen in the aeration process that landfill leachate goes through.

The aim of this work was to simulate the possible elimination of five SSRIs (citalopram, fluoxetine, paroxetine, sertraline and fluvoxamine) and three of their metabolites (desmethylcitalopram, didesmethylcitalopram and norfluoxetine) during aerobic treatment of leachate from landfills. Today, landfill leachates are treated with aeration in a pond/lagoon before infiltration into the environment. This landfill leachate-simulation experiment was performed to see what happens with the pharmaceuticals during aerated treatment and continuous stirring of landfill leachate for $120 \mathrm{~h}$. This experiment mimics the common process used for treatment of landfill leachate ponds and aims to predict the efficiency of pharmaceutical removal in aerated leachate ponds. It is important to establish whether different pollutants such as pharmaceuticals can be removed or not before infiltration into the environment. 


\section{Results and discussion}

\section{Aerobic treatment and oxygen consumption}

Due to the use of the pharmaceutical compounds as a carbon source combined with the carbon source in the leachate, we followed the changing concentrations of each SSRI in flasks with continuous stirring. Simultaneously, we followed the changing consumption of oxygen within the flasks headspace through $120 \mathrm{~h}$ (Figure 1). In landfill leachate, prescription and nonprescription pharmaceutical concentrations generally range from 100 to $10,000 \mathrm{ng} \mathrm{L}^{-1}$ [27]. The concentrations used in this experiment are somewhat higher than what is found before to enhance the effects seen on the experimental outcomes but are still regarded as environmentally relevant. Each type of SSRI with different concentrations could also give different oxygen consumption when present in landfill leachate, which again will be valuable information about the aerobic treatment of the landfill leachate.

Table 1 presents the ThOD for each SSRI, the total OC after 48 and $120 \mathrm{~h}$ and the measured OC minus the control sample (oxygen consumption of leachate) without SSRI. All the calculated ThODs show lower values
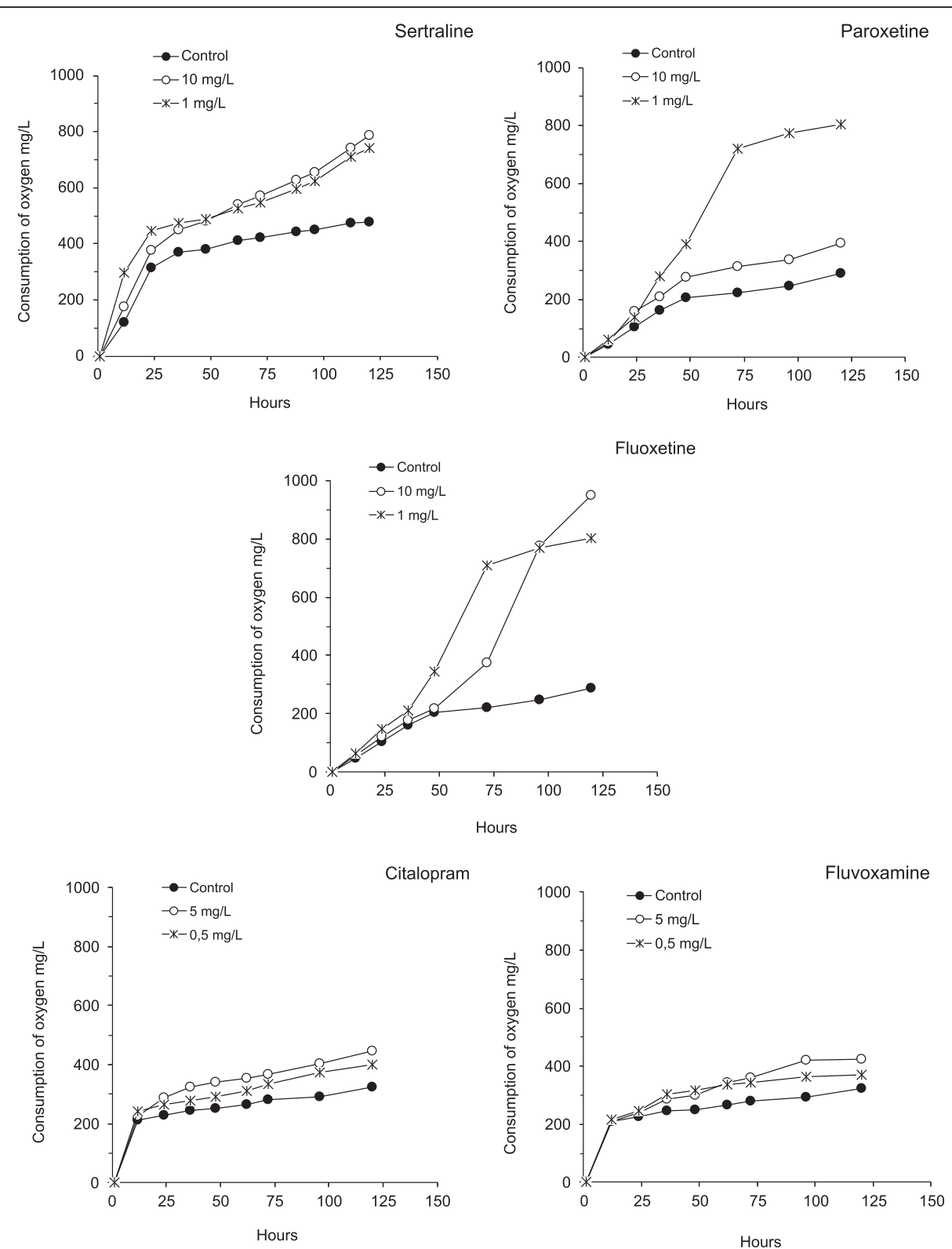

Figure 1 Total OC after $120 \mathrm{~h}$ in Voith Sapromat exposed to different concentrations of SSRIs in landfill leachate. Sertraline, paroxetine and fluoxetine 10 and $1 \mathrm{mg} \mathrm{L}^{-1}$; fluvoxamine and citalopram 5 and $0.5 \mathrm{mg} \mathrm{L}^{-1}$. Measured background respiration as control from leachate without SSRIs is included. 
Table 1 Theoretical and measured concentration of each SSRI spiked in leachate water before an aerobic treatment

\begin{tabular}{|c|c|c|c|c|c|c|c|}
\hline Source & $\begin{array}{l}\text { Theoretical } \\
\text { SSRI } \\
\mathrm{mg} \mathrm{L}^{-1}\end{array}$ & $\begin{array}{l}\text { Measured } \\
\text { SSRI } \\
\mathrm{mg} \mathrm{L}^{-1} \\
\end{array}$ & $\begin{array}{l}\text { (ThOD) } \\
\text { SSRI } \\
{\mathrm{mgO} 2 \mathrm{~L}^{-1}}\end{array}$ & 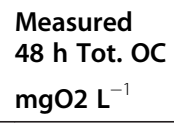 & $\begin{array}{l}\text { Measured } \\
120 \mathrm{~h} \text { Tot. OC } \\
\mathrm{mgO2} \mathrm{L}^{-1}\end{array}$ & $\begin{array}{l}\text { Measured } \\
48 \mathrm{~h} \mathrm{OC}^{*} \\
{\mathrm{mgO} 2 \mathrm{~L}^{-1}}\end{array}$ & $\begin{array}{c}\text { Measured } \\
120 \mathrm{~h} \mathrm{OC}^{*} \\
\mathrm{mgO2} \mathrm{L}^{-1} \\
\end{array}$ \\
\hline \multirow[t]{2}{*}{ Fluvoxamine } & 5 & 6 & 11.0 & 300 & 424 & 49 & 99 \\
\hline & 0.5 & 0.61 & 1.1 & 317 & 370 & 66 & 55 \\
\hline \multirow[t]{2}{*}{ Citalopram } & 5 & 3.2 & 13.1 & 340 & 445 & 89 & 120 \\
\hline & 0.5 & 0.39 & 1.3 & 290 & 401 & 39 & 76 \\
\hline \multirow[t]{2}{*}{ Sertraline } & 10 & 10 & 30.2 & 482 & 787 & 101 & 311 \\
\hline & 1 & 1.33 & 3.0 & 488 & 740 & 107 & 264 \\
\hline \multirow[t]{2}{*}{ Fluoxetine } & 10 & 11 & 22.8 & 340 & 950 & 135 & 661 \\
\hline & 1 & 0.84 & 2.3 & 290 & 802 & 85 & 513 \\
\hline \multirow[t]{2}{*}{ Paroxetine } & 10 & 14 & 22.4 & 278 & 395 & 73 & 106 \\
\hline & 1 & 1.31 & 2.2 & 393 & 803 & 188 & 514 \\
\hline
\end{tabular}

Measured oxygen consumption (Tot. OC) and OC* (Equation 1) after 48 and $120 \mathrm{~h}$ with each separate SSRI is compared with theoretical oxygen demand (ThOD) of SSRI tablets. The results of measured total OC are given as mean values $(n=2)$. *Equation 1.

than the measured OC after Equation 1 for each SSRI. All flasks spiked with the different SSRI tablets show dissimilar oxygen consumption, although considerably higher than the ThOD for each SSRI. This increased oxygen consumption in the flasks might be due to (i) cometabolism between each SSRIs plus tablets excipients and low decomposable carbon sources in the leachate, which was not accessible alone in the control flask; (ii) microbial co-metabolism between SSRIs and the carbon source from the excipients in the tablets alone. Each tablet mixture used contained approximately 20\% SSRIs and $80 \%$ excipients. Each SSRI tablet contains a large number of additives, e.g. carbon sources such as cellulose, starch and glycerol.

The high induced oxygen consumption observed in the flasks with paroxetine or fluoxetine in leachate substrate is most likely due to the excipients (Figure 1 and Table 1). Both these SSRI tablets have a higher amount of excipients than the other three SSRIs. The increased amount of excipient gave considerably higher oxygen consumption compared to the control samples and the other flasks spiked with fluvoxamine, citalopram or sertraline. Figure 1 and Table 1 also show that each SSRI gave an increased oxygen consumption compared to background consumption in the control flasks after a minimum of $50 \mathrm{~h}$ independent of SSRI concentration. After $120 \mathrm{~h}$ fluvoxamine shows less oxygen consumption in the flask with $0.5 \mathrm{mg}$ $\mathrm{L}^{-1}$, while the other SSRIs show increased oxygen consumption (Table 1). The diluted leachate solution without SSRIs had an initial $\mathrm{pH}$ of 7.1, and when spiking the samples with SSRIs, the $\mathrm{pH}$ increased in all samples due to the basic nature of the SSRIs (Table 2). The $\mathrm{pH}$ at start in

Table 2 SSRI concentrations and pH at the beginning and after $120 \mathrm{~h}$ of the experiment

\begin{tabular}{|c|c|c|c|c|c|c|c|c|c|}
\hline \multirow[b]{2}{*}{ SSRI } & \multicolumn{4}{|c|}{ Measured at start } & \multicolumn{5}{|c|}{ Measured at end } \\
\hline & $\begin{array}{l}\text { SSRI } \\
\mathrm{mg} \mathrm{L}^{-1}\end{array}$ & $\begin{array}{l}\text { STDEV } \\
\mathrm{mg} \mathrm{L}^{-1}\end{array}$ & $\begin{array}{l}\text { Rel. STDEV } \\
\%\end{array}$ & $\overline{\mathrm{pH}}$ & $\begin{array}{l}\text { SSRI } \\
\mathrm{mg} \mathrm{L}^{-1}\end{array}$ & $\begin{array}{l}\text { STDEV } \\
\mathrm{mg} \mathrm{L}^{-1}\end{array}$ & $\begin{array}{l}\text { Rel. STDEV } \\
\%\end{array}$ & $\mathrm{pH}$ & $\begin{array}{l}\text { Reduction } \\
\%\end{array}$ \\
\hline \multirow[t]{2}{*}{ Fluvoxamine } & 6.0 & 1.104 & 18 & 8.7 & 0.006 & 0.004 & 68 & 8.4 & 100 \\
\hline & 0.6 & 0.123 & 20 & 8.6 & 0.002 & 0.002 & 87 & 8.3 & 100 \\
\hline \multirow[t]{2}{*}{ Citalopram } & 3.2 & 0.102 & 3 & 9.1 & 0.005 & 0.001 & 16 & 8.5 & 100 \\
\hline & 0.4 & 0.026 & 7 & 9.0 & 0.002 & 0.001 & 11 & 8.6 & 100 \\
\hline \multirow[t]{2}{*}{ Sertraline } & 10.0 & 1.227 & 12 & 8.6 & 0.355 & 0.046 & 13 & 7.9 & 96 \\
\hline & 1.3 & 0.171 & 13 & 8.5 & 0.038 & 0.017 & 45 & 7.7 & 97 \\
\hline \multirow[t]{2}{*}{ Fluoxetine } & 11.0 & 0.873 & 8 & 9.2 & 0.805 & 0.063 & 8 & 8.1 & 93 \\
\hline & 0.8 & 0.156 & 18 & 9.0 & 0.003 & 0.001 & 14 & 8.0 & 100 \\
\hline \multirow[t]{2}{*}{ Norfluoxetine } & n.d. & & & & 0.006 & 0.001 & 11 & & \\
\hline & n.d. & & & n.d & n.d. & & & & \\
\hline \multirow[t]{2}{*}{ Paroxetine } & 14.0 & 0.163 & 1 & 9.8 & 0.105 & 0.011 & 11 & 8.0 & 99 \\
\hline & 1.3 & 0.143 & 11 & 9.6 & 0.141 & 0.003 & 2 & 7.9 & 89 \\
\hline
\end{tabular}


the samples varied between 8.5 (sertraline, low concentration) and 9.8 (paroxetine, high concentration). During the 120-h experiment, the $\mathrm{pH}$ was found to decrease in all samples, and the exact values can be seen in Table 2. This decrease in $\mathrm{pH}$ together with high oxygen consumption could support an explanation that the SSRIs spiked in the leachate have gone through an oxidation or are otherwise reduced in concentration.

Earlier SSRIs have been investigated under aerobic and anaerobic treatment processes of sewage waste to see if the SSRIs deplete or accumulate. Vasskog et al. [18] showed that all the SSRIs had a significant decrease in concentration during aerobic treatment in a composting process. Bergersen et al. [25] showed that paroxetine and citalopram were almost completely reduced during anaerobic treatment of sewage sludge while the lower reduction of fluoxetine, fluvoxamine and sertraline indicate that these three compounds have a higher potential for accumulation than citalopram and paroxetine under anaerobic conditions. A review describing removal or sorption of pharmaceuticals and other personal care products in water treatment such as natural wetland systems concludes that these systems have a high potential for removal of such chemicals [28]. One SSRI (fluoxetine) has been found to be removed from wetland systems by sorption into duckweed [29]. To our best knowledge, no studies have been conducted on SSRI depletion in landfill leachate ponds treated with aeration.

\section{Analysis and reduction of selective serotonin reuptake inhibitors}

The five selective serotonin reuptake inhibitors citalopram, sertraline, paroxetine, fluvoxamine and fluoxetine were analysed at the beginning and at the end of a 120-h experiment in a Voith Sapromat respirometer to investigate their concentration reduction during the process. The concentrations were calculated as $\mathrm{mg} \mathrm{L}^{-1}$ and compared with the total theoretical amount of each SSRI if no reduction had occurred in the samples. Table 1 shows the theoretical concentration, measured concentration and recovery of each SSRI before treatment. After treatment for $120 \mathrm{~h}$, all the SSRIs were measured at lower concentrations at the end of the experiment. The results shown in Table 2 give a detailed view of the concentration of each SSRI and the depletion throughout the experiment. All compounds showed a reduction in concentration of $89 \%$ to $100 \%$, independent of high- or low-start concentration. The recovery was measured at the beginning of the experiment and was generally high (between $64 \%$ and 140\%). The high recoveries of the SSRIs also imply that there is low or no binding to particles and humic acids in this experimental setup. There was no possibility to measure the recovery at the end of the experiment, but it is expected to be equal to that at the beginning. The highest recoveries (above 100\%) might be explained partly by the standard deviation but maybe more likely by the fact that the added SSRI is taken from crushed tablets. The weighed amount of the tablet might not have been homogenous and the sample withdrawn not representative. However, the main outcome of the experiment would be the same, showing the concentration reduction of the SSRIs during the experiment. There are small differences between the recovery of the high and low concentrations at the beginning of the experiment, which also indicate that the recovery should be more or less equal at even lower concentrations. Therefore, it is most likely that the low concentrations found at the end of the 120-h treatment were due to depletion of the compounds and not low recovery.

Likewise, their metabolites desmethylcitalopram, didesmethylcitalopram and norfluoxetine were analysed from the treated samples to determine whether they were formed during the experiment. Only one metabolite was found in the samples, and norfluoxetine was detected in a very low concentration $\left(0.006 \mathrm{mg} \mathrm{L}^{-1}\right)$ in the sample with an initially high fluoxetine concentration (Table 2).

The experiment is set up to simulate the conditions in a landfill leachate pond, and it is reasonable to believe that the pharmaceuticals will have a similar degradation profile in a full-size treatment system treated with aeration for days or weeks.

The results in this experiment differ from earlier experiments, where the same SSRIs were measured during an aerobic composting and anaerobic sewage sludge treatment $[8,25]$. By comparing the results from the aerobic and anaerobic experiment with this experiment, both similarities and differences are found.

Table 3 illustrates a comparison of three different treatment processes that show reduction efficiency and reduction rate for all five SSRIs. First: All SSRIs show considerable higher reduction rate in an aqueous aerated media (Table 3). Second: In the aerobic composting process [18], fluvoxamine and paroxetine had the highest reduction rates, while in the anaerobic experiment

Table 3 Comparison of the reduction rates of SSRIs with different treatment methods

\begin{tabular}{llll}
\hline SSRI & $\begin{array}{l}\text { Aerobic sludge } \\
\text { composting [18] }\end{array}$ & $\begin{array}{l}\text { Anaerobic sludge } \\
\text { treatment [25] }\end{array}$ & $\begin{array}{l}\text { Aeration treatment } \\
\text { landfill leachate }\end{array}$ \\
& $\begin{array}{l}\text { Reduction rate } \\
\text { (\% per 21 days) }\end{array}$ & $\begin{array}{l}\text { Reduction rate } \\
\text { (\% per 24 days) }\end{array}$ & $\begin{array}{l}\text { Reduction rate } \\
\text { (\% per 5 days) }\end{array}$ \\
\hline Fluvoxamine & 88 & 53 & 100 \\
Citalopram & $26^{\mathrm{a}}$ & 85 & 100 \\
Sertraline & $46^{\mathrm{a}}$ & 38 & 96 \\
Fluoxetine & $35^{\mathrm{a}}$ & 32 & $93^{\mathrm{a}}$ \\
Paroxetine & 46 & 98 & 90 \\
\hline
\end{tabular}

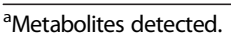


[25], paroxetine still had a high reduction rate while fluoxetine had a very low reduction rate. The metabolite norfluoxetine was detected in both aerobic experiments while it was absent after anaerobic treatment. Third: Citalopram was the most stable SSRI in the aerobic composting experiment, while in the anaerobic sewage sludge and in this aerated treatment experiment, it was quickly reduced in concentration. Based on this experiment, we can only assume that the differences in stability in these three experiments might be due to the different bacteria present in aerobic and anaerobic systems, but it could also originate from different chemical reactions in the three systems since we cannot determine whether the concentration reduction is due to chemical or biological degradation.

We are limited in the extent to which it is possible to compare three functionally different systems, especially when we consider the variability in pharmaceutical stability under different conditions. Table 3 clearly shows that the availability factor for degradation of each SSRI is higher in aqueous medium compared to solid-phase medium like the composting system. SSRI degradation in a solid-phase medium also gave detection of three different metabolites from five different SSRIs after the biological treatment. Independent of anaerobic or aeration treatment, SSRIs in aqueous solution gave considerably higher reduction rates.

\section{Conclusions}

Selective serotonin reuptake inhibitors can be effectively reduced in concentration by aerobic treatment of landfill leachates. The concentration reduction was close to complete for all compounds in both concentrations during the experimental time of $120 \mathrm{~h}$. Only one of the known human metabolites (norfluoxetine) was found in the aeration samples, which suggests other degradation products than those formed by the human metabolism. Comparing the results of all SSRIs with different treatment methods, paroxetine and fluvoxamine seem to be the easiest compounds to eliminate independent of method, while fluoxetine and sertraline seem to be the most stable.

Our results suggest that aeration is an effective method for minimising the impact of pharmaceuticals such as SSRIs from landfill leachates water. However, further studies are required to determine what kind of degradation products are formed, and based on such results, preventive actions in the form of more sophisticated water treatment systems can be made.

\section{Methods}

\section{Aerobic treatment experiment}

Leachate from an active landfill $(3 \mathrm{~L})$ was diluted with water $(10 \mathrm{~L})$, and the composition of the leachate is given in Table 4. Table 4 shows the content of the leachate with carbon source as total organic carbon (TOC), organic acids and Total- $\mathrm{N}$ that will enhance microbial activity. The strategy of the experiment was to measure the microbial respiration in the leachate solution spiked with SSRI tablets and compare it to control flasks with diluted leachate water without addition of tablets.

Pharmaceutical pollution from landfill leachates will be as unused tablets or from tablet packages. Therefore, the stock solution was made up of crushed tablets of each SSRI that was dissolved in $30 \mathrm{~mL}$ methanol $(\mathrm{MeOH}$, Merck, Darmstadt, Germany) and then diluted with $270 \mathrm{~mL}$ distilled water, stirred and heated for $2 \mathrm{~h}$ at $35^{\circ} \mathrm{C}$ and stored at $4^{\circ} \mathrm{C}$ until used. Diluted leachate in $500-\mathrm{mL}$ flasks was spiked with a stock solution of the different SSRIs. The theoretical starting concentration was 5 and $0.5 \mathrm{mg} \mathrm{L}^{-1}$ for fluvoxamine and citalopram and 10 and $1 \mathrm{mg} \mathrm{L}^{-1}$ for sertraline, fluoxetine and paroxetine.

The flasks with leachate water were incubated in a water bath in a Voith Sapromat respirometer (Voith, Heldenheim/Brenz, Gemany) [30]. The Voith Sapromat continuously measure consumption of oxygen in solutions and the developed $\mathrm{CO}_{2}$ gas in the flask is trapped with $\mathrm{NaOH}$ (Merck). The experiment was performed in duplicates, and the samples were incubated for $120 \mathrm{~h}$ at $20^{\circ} \mathrm{C}$ in darkness. The samples were stirred continuously in closed flasks with a magnet. Total oxygen consumption (Tot. OC) was calculated from the whole tablet mixture with all excipients, with the background respiration from the leachate after 48 and $120 \mathrm{~h}$, while the

Table 4 Chemical analysis of leachate water after dilution used in the Voith Sapromat respirometer experiment

\begin{tabular}{llll}
\hline Parameter & Units & Raw material & $\begin{array}{l}\text { Diluted } \\
\text { leachate }\end{array}$ \\
\hline TOC & $\mathrm{mg} \mathrm{L}^{-1}$ & 773 & 178 \\
Tot-N & $\mathrm{mg} \mathrm{L}^{-1}$ & 322 & 74 \\
Tot-S & $\mathrm{mg} \mathrm{L}^{-1}$ & 21 & 4.8 \\
SO4 & $\mathrm{mg} \mathrm{L}^{-1}$ & 0.3 & 0.1 \\
Fe & $\mathrm{mg} \mathrm{L}^{-1}$ & 16 & 3.7 \\
Formic acid & $\mathrm{mg} \mathrm{L}^{-1}$ & 31 & 7.2 \\
Acetic acid & $\mathrm{mg} \mathrm{L}^{-1}$ & 5.6 & 1.3 \\
Propionic acid & $\mathrm{mg} \mathrm{L}^{-1}$ & 1.1 & 0.25 \\
Butanoic acid & $\mathrm{mg} \mathrm{L}^{-1}$ & 1.5 & 0.3 \\
Pentanoic acid & $\mathrm{mg} \mathrm{L}^{-1}$ & 3.2 & 0.7 \\
Hexanoic acid & $\mathrm{mg} \mathrm{L}^{-1}$ & 2.4 & 0.6 \\
Heptanoic acid & $\mathrm{mg} \mathrm{L}^{-1}$ & 1.3 & 0.3 \\
DL- lactat & $\mathrm{mg} \mathrm{L}^{-1}$ & 5.5 & 1.3 \\
BOD 7 & $\mathrm{mg} \mathrm{L}^{-1}$ & 430 & \\
Redox potential & $\mathrm{mV}_{\text {pH }}$ & -148 & 6.9 \\
\hline
\end{tabular}


oxygen consumption $(\mathrm{OC})^{*}$ (Equation 1) was calculated from the whole tablet mixture with all excipients, with the background respiration from the leachate (Equation 1) subtracted. Theoretical oxygen demand (ThOD) for each SSRI was calculated using the Buswell equation [31]. The SSRI tablets contain a large number of additives, e.g. carbon sources such as cellulose, starch and glycerol. The tablet mixture used in our experiment contains approximately $20 \%$ SSRIs and $80 \%$ excipients.

$$
\begin{gathered}
\text { Measured } \mathrm{OC}_{j}=\operatorname{Measured}\left(\mathrm{OC} h_{j}-\mathrm{OC} h, \text { control }\right) \\
\left(\operatorname{mg} \text { oxygen } \mathrm{L}^{-1}\right) \\
\text { OC } \text { hours }_{j}=\begin{array}{c}
\text { Measured oxygen consumption of each } \\
\text { SSRI }\left(\text { mg oxygen } L^{-1}\right)
\end{array}
\end{gathered}
$$

OC hours, control $=$ Measured oxygen consumption leachate $\left(m g\right.$ oxygen $\left.L^{-1}\right)$

\section{Chemicals and solvents}

Standards of the SSRIs citalopram (1-[3-(dimethylamino) propyl]-1-(4-fluorophenyl)-1,3-dihydro- 5-isobenzofuran carbonitrile), sertraline ((1S-cis)-4-(3,4-dichlorophenyl)1,2,3,4-tetrahydro-N-methyl-1-naphtylamine), paroxetine (trans-(-)-3-[(1,3-benzo-dioxol-5-yloxy) methyl]benzene propanamine), fluvoxamine (5-methoxy-1-[4-(trifluoro methyl)-phenyl]-1-pentanone-O-(2-aminoethyl)oxime) and fluoxetine $(( \pm)-\mathrm{N}$-methyl- $\gamma$-[4(trifluoromethyl)phenoxy] benzenepropanamine), and the metabolites desmethyl citalopram (1-(4-fluorophenyl)-1,3-dihydro-1-[3-(methy lamino)propyl]-5-isobenzofurancarbonitrile), didesmet hylcitalopram (1-(3-aminopropyl)-1-(4-fluorophenyl)1,3-dihydro-5-isobenzofurancarbonitrile) and norfluoxetine $(\gamma$-[4-(trifluoromethyl)phenoxy]-benzenepropanamine), and the deuterated standards $\mathrm{D}_{3}$-sertraline, $\mathrm{D}_{4}$-paroxetine, $\mathrm{D}_{5}$-fluoxetine and $\mathrm{D}_{6}$-citalopram were purchased from Toronto Research Chemicals (Toronto, ON, Canada). The mass spectrometric identification criteria, recoveries, LOD and LOQ and pKa-values for the compounds are given in Table 5. pKa values are calculated by Advanced Chemistry Development (ACD/Labs) Software V8.14 for Solaris, obtained from SciFinder Scholar 2010.

The isotope labelled compounds were used as internal standards (IS) for quantification. All standards were delivered with purity above $98 \%$. Escitalopram, which is the pure S-enantiomer of citalopram, is not possible to distinguish from the R-enantiomer with our analytical techniques, and these enantiomers are measured as the same compound.

The standards were dissolved in HPLC-grade $\mathrm{MeOH}$ from Merck in concentrations of 100 or $200 \mu \mathrm{g} \mathrm{mL} \mathrm{m}^{-1}$, stored at $-18^{\circ} \mathrm{C}$ in the dark and used as stock solutions. From this stock solution, the daily work solutions were made by dilution with purified water.

Solvents for HPLC were HPLC-grade acetonitrile from Merck, purified water obtained from a MilliQ purification unit from Millipore (Bedford, MA, USA) and proanalysis-grade formic acid from Merck. The same water and formic acid were used for liquid-phase microextraction (LPME), while dihexyl ether (purum $\geq 97 \%$ ) from FLUKA (Buchs, Switzerland) was used as organic solvent to fill the pores of the fibre.

\section{Chemical analysis}

The samples were mixed with deionized water (ratio 1:2 by volume) and the $\mathrm{pH}$ was measured $30 \mathrm{~min}$ after mixing with a Ross electrode (Orion Instruments, Baton

\begin{tabular}{|c|c|c|c|c|c|c|c|c|c|}
\hline Compound & pKa & $\begin{array}{l}{[\mathrm{M}+\mathrm{H}]+} \\
\text { (measured) }\end{array}$ & $\begin{array}{l}\text { Fragment } \\
\text { (measured) }\end{array}$ & $\begin{array}{l}\text { Cone } \\
\text { voltage }\end{array}$ & $\begin{array}{l}\text { Collision } \\
\text { energy }\end{array}$ & $\begin{array}{l}\text { Retention } \\
\text { time (min) }\end{array}$ & $\operatorname{LOD}\left(\mathrm{pg} \mathrm{L}^{-1}\right)$ & LOQ $\left(p g L^{-1}\right)$ & $\begin{array}{l}\text { Extraction } \\
\text { recovery (\%) }\end{array}$ \\
\hline Citalopram & 9.59 & 325.5 & 108.6 & 35 & 25 & 3.3 & 20 & 60 & $64 / 78^{a}$ \\
\hline Desmethylcitalopram & 9.41 & 311.1 & 108.5 & 28 & 25 & 3.1 & 230 & 760 & - \\
\hline Didesmethylcitalopram & 10.14 & 297.1 & 108.5 & 29 & 20 & 2.9 & 200 & 780 & - \\
\hline Citalopram-D6 (IS) & - & 331.2 & 108.6 & 41 & 27 & 3.3 & - & - & - \\
\hline Paroxetine & 10.05 & 330.2 & 69.6 & 40 & 22 & 4.1 & 50 & 205 & $140 / 131^{a}$ \\
\hline Paroxetine-D4 (IS) & - & 334.2 & 73.7 & 40 & 29 & 4.1 & - & - & - \\
\hline Fluvoxamine & 9.39 & 319.1 & 70.6 & 24 & 17 & 4.8 & 130 & 380 & $120 / 122^{a}$ \\
\hline Fluoxetine & 10.05 & 310.1 & 43.8 & 22 & 15 & 6.0 & 150 & 490 & $110 / 84^{a}$ \\
\hline Norfluoxetine & 9.05 & 296.1 & 133.7 & 15 & 5 & 5.5 & 160 & 540 & - \\
\hline Fluoxetine-D5 (IS) & - & 315.2 & 43.8 & 20 & 12 & 6.0 & - & - & - \\
\hline Sertraline & 9.47 & 306.1 & 158.6 & 18 & 25 & 6.4 & 160 & 520 & $100 / 133^{a}$ \\
\hline Sertraline-D3 (IS) & - & 309.1 & 274.8 & 17 & 12 & 6.4 & - & - & - \\
\hline
\end{tabular}
Rouge, USA). The redox potential in the leachate was

Table 5 Identification criteria, extraction recoveries, LOD, LOQ, pKa and mass spectrometric detection parameters for the different SSRIs

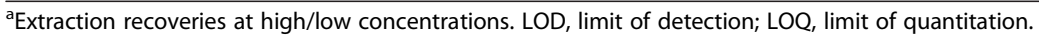


analysed by an ATI ORION (Orion Instruments) and conductivity by a Phillips PW 9527 digital meter (Philips, Eindhoven, Netherlands).

Inorganic parameters of the leachate illustrated in Table 4 were analysed by an accredited laboratory (Eurofins AS) using Norwegian standards regarding total nitrogen (Tot-N), TOC, biochemical oxygen demand (BOD7), total sulphur (Tot-S), $\mathrm{SO}_{4}$ and iron [32]. The leachate water was also characterized with respect to content of short-chained organic acids. The organic acids in the leachate water used in the experiment were alkaline extracted by adding $0.1 \mathrm{M} \mathrm{NaOH}$ (Merck) to the samples. Concentrated $\mathrm{HCl}$ (pro analysis, Merck) was then added to the water phase and undissociated acids were then extracted with diethyl ether ( $>98 \%$, Merck) and further derivatized by t-butyldimethylsilyl ( $>99 \%$ Sigma Aldrich, St. Louis, USA) and measured on a gas chromatograph-mass spectrometer (GC-MS) with electron impact ionization (EI) after a method described by Schooley et al. [33].

All samples taken during the experiment were stored in a freezer at $-18^{\circ} \mathrm{C}$ before chemical extraction and analysis. Three replicate liquid-phase microextraction analyses of the SSRIs and metabolites were performed.

An already developed extraction method known as hollow fibre-supported liquid-phase microextraction (HFLPME or just LPME) was employed to extract the SSRIs and their metabolites from the samples. The method development is described elsewhere [34], and only a brief description will be given here. Since the SSRI concentration in the leachate water samples was relatively high, and the LPME method has proved to be very sensitive for the SSRIs [8], the samples were diluted to a concentration in the high end of the calibration curve prior to extraction (200 $\mathrm{ng} \mathrm{L}^{-1}$ ). The dilution was done with deionized water to a total volume of $1.1 \mathrm{~L}$. The isotope labelled internal standards was added in a concentration of $50 \mathrm{ng} \mathrm{L}^{-1}$, and the $\mathrm{pH}$ was adjusted to 12 with $5 \mathrm{M} \mathrm{NaOH}$ (Merck) before the samples were extracted by LPME. Three replicates were analysed from each of the selected days.

A 28-cm-long plasmaphan polypropylene hollow fibre (Membrana, Wuppertal, Germany) was used for the extraction, and the pores of the fibre were filled with dihexyl ether by dipping the hollow fibre into the solvent for $10 \mathrm{~s}$. The excess ether on the fibre surface was removed by dipping it in an ultrasonic bath for 2 to $3 \mathrm{~s}$. Then the fibre lumen was filled with $20-\mu \mathrm{L}$ acceptor phase (purified water/formic acid at $\mathrm{pH} 2$ ), and the ends of the fibre were sealed with a thin metal wire. The same wire was used to keep the fibre hanging in the middle of the sample bottle. The samples were stirred for $2 \mathrm{~h}$ at 800 RPM. After extraction, the extracts were transferred to Waters (Milford, MA, USA) total recovery HPLCvials and analysed using HPLC-MS/MS. The separation was conducted on a Waters Acquity UPLC BEH $\mathrm{C}_{18}$ column $(1.0 \times 150 \mathrm{~mm}$ with $1.7-\mu \mathrm{m}$ particles $)$, and the mobile phases consisted of $\mathrm{A}: \mathrm{H}_{2} \mathrm{O}$ and $0.1 \%$ formic acid and B: $90 \%$ acetonitrile, $9.9 \% \mathrm{H}_{2} \mathrm{O}$ and $0.1 \%$ formic acid. The gradient started with a 1-min isocratic elution with $70 \% \mathrm{~A}$ and $30 \% \mathrm{~B}$; from 1 to $7 \mathrm{~min}$, there was a linear change in composition to $55 \% \mathrm{~A}$ and $45 \% \mathrm{~B}$ and finally a linear change from 7 to $12 \mathrm{~min}$ to $50 \% \mathrm{~A}$ and $50 \% \mathrm{~B}$. The flow rate was set to $50 \mu \mathrm{L} \mathrm{min}{ }^{-1}$. The mass spectrometric detection was done on a triple quadrupole instrument (Waters Quattro Premier XE) in multiple reactions monitoring mode with positive electrospray ionization for optimal selectivity and sensitivity. The protonated molecular ion $[\mathrm{M}+\mathrm{H}]^{+}$was used as a precursor ion for all compounds, and the most intense product ion was selected for quantification (see Table 2).

\section{Calibration curves}

Calibration curves were made in the concentration range 1 to $250 \mathrm{ng} \mathrm{L}^{-1}$. The standard samples were set up and extracted in the same way as the leachate water samples. Standard samples were extracted and analysed throughout the experiment period to ensure that the calibration curves were constant over time. Four internal standards were used for quantification. Sertraline was quantified with $\mathrm{D}_{3}$-sertraline as IS; paroxetine with $\mathrm{D}_{4}$-paroxetine; fluvoxamine, fluoxetine and norfluoxetine with $\mathrm{D}_{3}$-fluoxetine; and citalopram, desmethylcitalopram and didesmethylcitalopram with $\mathrm{D}_{6}$-citalopram as IS. The linearity $\left(R^{2}\right)$ of the method ranged between 0.9997 (paroxetine) and 0.9894 (fluvoxamine) and was considered as good for all compounds in this concentration range. The linearity of fluvoxamine was a little lower than for the rest of the compounds, most likely because no isotope labelled IS was available for this compound.

The concentration measurements were done on the basis of the peak area of the analyte divided by the peak area of the IS, and all concentrations were analysed in triplicate for each concentration.

\section{Quality control}

The identification criteria of the SSRIs are given in Table 5 and consist of correct retention time and the correct ion transition. Ideally, two or more product ions should be analysed in the mass spectrometric analysis, but for four of the five SSRIs, the second product ion is of too low intensity to be seen at the relevant concentrations; hence, only the most intense ion was used.

The methods limit of detection and limit of quantification was found by extracting and analysing a dilution series of standards in leachate water, and the limits are given in Table 5. Three parallels of each concentration were analysed. 
All leachate water samples were extracted and analysed in triplicate. Between every third sample (nine injections), a blank sample of purified water was analysed to check for carry-over signals. No carry-over was detected.

\section{Competing interests}

The authors declare that they have no competing interests.

\section{Authors' contributions}

The authors $\mathrm{OB}$ and TV are responsible for the concept and design of the study. OB has also performed the aerobic treatment of the landfill leachate including the measurements of TOC, Tot- $\mathrm{N}$, Tot-S, $\mathrm{SO}_{4}$ and Fe, as well as writing of the manuscript. TV also developed the extraction and LC-MS methods used in the experiment, as well as result interpretation and writing of the manuscript. $\mathrm{KØH}$ performed the extractions of the samples, set up standard curves and calculated concentrations, as well as participated in discussions of methods and results. All authors read and approved the final manuscript.

\section{Acknowledgements}

Financial support for this project was provided by Bioforsk and the Norwegian Research Council through the 'Pharmatreat' project (project number 171738/S30).

\section{Author details \\ ${ }^{1}$ Norwegian Institute for Agricultural and Environmental Research (Bioforsk), Soil and Environment Division, Fredrik A Dahls vei 20, N-1432 Ås, Norway. ${ }^{2}$ Department of Pharmacy, Faculty of Health Sciences, University of Troms $\varnothing$, N-9037 Tromsø, Norway. ${ }^{3}$ Norut (Northern Research Institute), N-9294 Tromsø, Norway.}

Received: 14 August 2014 Accepted: 22 December 2014 Published online: 28 January 2015

\section{References}

1. Daughton CG, Ternes TA. Pharmaceuticals and personal care products in the environment: agents of subtle change. Environ Health Perspect. 1999:107:907-38.

2. Heberer T. Occurrence, fate, and removal of pharmaceutical residues in the aquatic environment: a review of recent research data. Toxicol Lett. 2002;131:5-17

3. Sanderson H, Johnson DJ, Reitsma T, Brain RA, Wilson CJ, Solomon KR. Ranking and prioritization of environmental risks of pharmaceuticals in surface waters. Regul Toxicol Pharmacol. 2004;39:158-83.

4. Fent K, Weston AA, Caminada D. Ecotoxicology of human pharmaceuticals. Aquat Toxicol. 2006;76:122-59.

5. Ternes TA. Occurrence of drugs in German sewage treatment plants and rivers. Water Res. 1998;32:3345-260.

6. Simonich SL, Federle TW, Eckhoff WS, Rottiers A, Webb S, Sabaliunas D, et al Removal of fragrance materials during U.S. and European wastewater treatment. Environ Sci Technol. 2002;36:2839-47.

7. Carballa M, Omil F, Lema JM, Llompart M, Garcia-Jares C, Rodriguez I, et al. Behavior of pharmaceuticals, cosmetics and hormones in a sewage treatment plant. Water Res. 2004:38:2918-26.

8. Vasskog T, Anderssen T, Pedersen-Bjergaard S, Kallenborn R, Jensen E. Occurrence of selective serotonin reuptake inhibitors in sewage and receiving waters at Spitsbergen and in Norway. J Chrom A. 2008;1185:194-205.

9. Jux U, Baginski RM, Arnold H-G, Krönke M, Seng PN. Detection of pharmaceutical contaminations of river, pond, and tap water from Cologne (Germany) and surroundings. Int J Hyg Environ Health. 2002;205:393-8.

10. Kolpin DW, Furlong ET, Meyer MT, Thurman EM, Zaugg SD, Barber LB, et al. Pharmaceuticals, hormones, and other organic wastewater contaminants in U.S. streams, 1999-2000: a national reconnaissance. Environ Sci Technol. 2002:36:1202-11.

11. Holm JV, Rügge K, Bjerg PL, Christensen TH. Occurrence and distribution of pharmaceutical organic compounds in the groundwater downgradient of a landfill (Grindsted, Denmark). Environ Sci Technol. 1995;29:1415-20.
12. Lapworth DJ, Baran N, Stuart ME, Ward RS. Emerging organic contaminants in groundwater: a review of sources, fate and occurrence. Environ Pollut. 2012;163:287-303.

13. The Norwegian Institute of Public Health. Report; Drug consumption statistics 2012:1 - drug consumption in Norway 2007-2011. ISBN-electronic: 978-82-8082-491-2.

14. Vasskog T, Berger U, Samuelsen P-J, Kallenborn R, Jensen E. Selective serotonin reuptake inhibitors in sewage influents and effluents from Troms $\varnothing$, Norway. J Chrom A. 2006;1115:187-95.

15. Pittman JT, Ichikawa KM. iPhone ${ }^{\circledast}$ applications as versatile video tracking tools to analyse behaviour in zebrafish (Danio rerio). Pharmacol Biochem Behav. 2013;106:137-42.

16. Fong PP, Molnar N. Norfluoxetine induces spawning and parturition in estuarine and freshwater bivalves. Bull Environ Contamin Toxicol. 2008;81:535-8.

17. Bringolf RB, Heltsley RM, Newton TJ, Eads CB, Fraley SJ, Shea D, et al. Environmental occurrence and reproductive effects of the pharmaceutical fluoxetine in native freshwater mussels. Environ Toxicol Chem. 2010;29:1311-8.

18. Vasskog T, Bergersen O, Anderssen T, Jensen E, Eggen T. Depletion of selective serotonin reuptake inhibitors during sewage sludge composting. Waste Managem. 2009:29:2808-15.

19. Carballa M, Omil F, Ternes T, Lema JM. Fate of pharmaceutical and personal care products (PPCPs) during anaerobic digestion of sewage sludge. Water Res. 2007;41:2139-50.

20. Vieno N, Tuhkanen T, Kronberg L. Elimination of pharmaceuticals in sewage treatment plants in Finland. Water Res. 2007;41:1001-12.

21. Musson SE, Campo P, Tolaymat T, Suidan M, Townsend TG. Assessment of the anaerobic degradation of six active pharmaceutical ingredients. Sci Total Environ. 2010;408(9):2068-74.

22. Paterakis N, Chiu TY, Koh YKK, Lester JN, McAdam EJ, Scrimshaw MD, et al. The effectiveness of anaerobic digestion in removing estrogens and nonylphenol ethoxylates. J Hazard Mater. 2012;199-200:88-95.

23. de Graaff MS, Vieno NM, Kujawa-Roelveld K, Zeeman G, Temmink H, Buisman CJN. Fate of hormones and pharmaceuticals during combined anaerobic treatment and nitrogen removal by partial nitritation-anammox in vacuum collected black water. Water Res. 2011;45:375-83.

24. Falås P, Baillon-Dhumez A, Andersen HR, Ledin A, la Cour JJ. Suspended biofilm carrier and activated sludge removal of acidic pharmaceuticals. Water Res. 2012;46:1167-75.

25. Bergersen $\mathrm{O}$, Hanssen $\mathrm{KO}$, Vasskog $\mathrm{T}$. Anaerobic treatment of sewage sludge containing selective serotonin reuptake inhibitors. Biores Technol. 2012;117:325-32.

26. Eggen T, Moeder M, Arukwe A. Municipal landfill leachate: a significant source for new and emerging pollutions. Sci Total Environ. 2010;408:5147-57.

27. Demas A, Kolpin D. Technical announcement: pharmaceuticals and other chemicals common in landfill waste. US Department of the Interior: US Geological Survey; 8/11/2014.

28. Haarstad K, Bavor HJ, Mæhlum T. Organic and metallic pollutants in water treatment and natural wetlands: a review. Water Sci Technol. 2012;65:176-99.

29. Reinholdt D, Vishwanathan S, Park JJ, Oh D, Saunders FM. Assessment of plant-driven removal of emerging organic pollutants by duckweed. Chemosphere. 2010;80:687-92.

30. Bouchez M, Blanchet D, Besnainou B, Leveau J, Vendercasteele JP. Kinetic studies of biodegradation of insoluble compounds by continuous determination of oxygen consumption. J Appl Microbiol. 1997;82:310-6.

31. Tchobanoglous $\mathrm{G}$, Theisen H, Vigil S. Integrated solids waste management. New York: McGraw-Hill; 1993.

32. Norwegian standards (NS-EN ISO/IEC 17025): Tot N (modified NS 4743), TOC (AJ 31 /NS-EN 13137), BOD7 (AV110/NS 4758) Tot S (AVJ and AVI/ ICP-AES) $\mathrm{SO}_{4}(\mathrm{AV} 10 / \mathrm{IC}$ ) and Fe by (AVJ and AVI/ ICP-AES). Metal analyses from the filter material by (AVI/ ICP-AES). http://www.standard.no/imaker.exe?id=4162. (accessed 2008)

33. Schooley DL, Kubiak FM, Evans JW. Capillary gas chromatographic analysis of volatile and non-volatile organic acids from biological samples as the t-butyldimetylsilyl derivatives. J Chrom Sci. 1985;23(9):385-90.

34. Ho TS, Vasskog T, Anderssen T, Jensen E, Rasmussen KE, Pedersen-Bjergaard S. 25,000-fold pre-concentration in a single step with liquid-phase microextraction. Anal Chim Acta. 2007;592:1-8. 